\title{
Occult Papillary Carcinoma of Thyroid with Postoperative Tuberculous Lymphadenitis
}

\author{
S M Khodeza Nahar Begum', A B M A Hannan ${ }^{2}$, Saiful Islam³ , Dayem Uddin ${ }^{4}$, ARM Saifuddin Ekram ${ }^{6}$
}

\begin{abstract}
A 40-year-old female presented with tuberculous cervical lymphadenopathy developed within three months of total thyroidectomy operation. Her thyroid lesion was a nodular goiter harboring occult papillary carcinoma. Aspiration cytology and histopathology of lymph node revealed granulomatous lymphadenitis of tuberculous type. The patient was treated with conventional antituberculous four-drug regime for 6 months and was followed up for subsequent two years. Our country is considered as an endemic goiter area and Occult papillary carcinoma is therefore, not an uncommon disease here. Tuberculosis is a communicable disease also seen frequently here. But development of tuberculous lymphadenitis in a postoperative Thyroidectomy patient has not been reported before, as per authors knowledge goes. This case has therefore been reported here with a brief review of the literature. This is also emphasized here, that occult papillary carcinoma is possibly a noniethal curable disease when treated by conservative surgery. Radical surgical or total thyroidectomy is unnecessary in the treatment of the disease. Postoperative nodal metastasis is also of yery rare occurrence with these cases.
\end{abstract}

TAJ 2001; 14(2): 92-95

\section{Introduction}

Papillary microcarcinoma (occult papillary carcinoma occult sclerosing carcinoma) is a term given to small papillary carcinoma less than $1 \mathrm{~cm}$. in diameter that may have a central fibrous car. ${ }^{1.2}$ Usually these are discovered incidentally at autopsy, by chance in thyroid glands resected because of nodular goiter (NG) or in an ipsilateral lobe removed subsequent to the finding of thyroid cancer metastatic in an enlarged cervical lymph node. ${ }^{3}$ The prevalence rate of occult papillary carcinoma (OPC) has been reported to be higher in males than in females in some autopsy series containing mainly older peoples. This male predominance contrasts to the approximately three times higher incidence of clinical papillary carcinoma in females. Some other authors reported that there is no significant difference between prevalence in males and females. ${ }^{4}$

Hazard et al ${ }^{5}$ considered occult sclerosing carcinomas as benign tumours, but later studies have shown that these lesions are malignant slow growing neoplasm's which occasionally metastasize to the ceryical lymph nodes and rarely to distant sites via the blood vesseis. ${ }^{6,7}$ FNAC has

Consultant Histopathologist and Cycologist, Xyla Medicare Complax, Rajshahi-6000, Bangladesh

zAsspciate Professor, Department ol Surgary. Rajshahi Modical College Hospital, Rajshahi-6000, Bangladesh.

${ }^{5}$ Assistant Professor, Department of ENT, Rajshahi Medical College Hospital, Rajshahi-6000. Bangladesh.

'Associate Protessor, Depertment of Radiotherady. Rajshahi Medical College Hospital, Rajshehi-6000. Bangladesh.

? Asscciate Prolessor, Department of Medicine, Rajshahi Medical College Hospolal. Aajashahi-6000 Bangladesh 
proved its usefulness in the diagnosis of a wide variety of benign and malignant neoplasms This procedure is also very valuable in the diagnosis of opportunistic infections including fungal and bacterial infections. ${ }^{8.9}$ Ultrasonography followed by US-guided-FNAC could be a useful routine method of evaluating thyroid tumors. ${ }^{10.11}$ In this particular case US-FNAC of the thyroid revealed presence of occult papillary carcinoma and FNAC of the cervical lymph node revealed features of tuberculous lymphadenopathy.

\section{Case History}

A 40 year old female presented to Rajshahi medical College Hospital with enlarged thyroid gland. On examination a multinodular thyroid swelling was seen involving its left lobe. No regional enlarged lymph node was found. Routine blood examination revealed unremarkable findings. Thyroid function tests showed slightly raised TSH level. Thyroid scan revealed an asymmetrical uptake, Conventional FNAC was performed which was suggestive of colloid goiter. Ultrasonography of thyroid gland revealed a suspicious hypoechoic nodule (1 cm. diameter) in the left lobe near its capsule. An US-guided FNAC was therefore arranged. One pass was performed through the solid nodule and two in random order. All the smears revealed features of colloid goiter except from one site (which during US seemed to be a more hypoechoic lesion) which cytologically represented papillary carcinoma. A total thyroidectomy operation was performed and the specimen was submitted for histopathological examination. The specimen on gross observation appeared multinodulated. The gland was transversely and serially sectioned at $2-3 \mathrm{~mm}$ intervals. A grossly identifiable encapsulated tiny gray-white lesion was seen (Approx. $0.9 \mathrm{~cm}$. in diameter) at one focus near to its capsule. Three blocks were embedded; one from the suspicious area and the other two from elsewhere. On microscopic examination the suspected lesion was found to be a malignant tumour (Fig-1). The anaplastic cells had pale cytoplasm and large vesicular ground glass appearing nuclei (more than $50 \%$ cells) largely disposed in delicate papillae.
Fibrous tissue proliferation and mild lymphocytic reaction was seen around the tumour. Besides the lesion the rest of the sections revealed evidences of nodular goiter. The patient was discharged and was advised for radioiodine scanning and $\mathrm{I}^{13\}}$ ablation therapy. She however did not return for observation until after 3 months of operation. Her operation scat was perfectly all right but a mass was clearly apparent in left anterior triangle of het neck at jugulodigastric site.

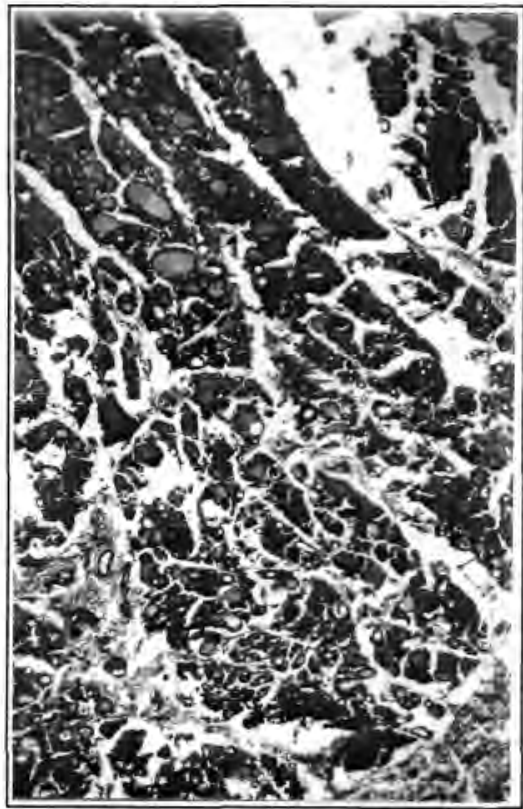

Fig-1:

It was an enlarged cervical lymph node and was suspected to be a metastatic lesion. FNAC was performed which revealed caseous necrotic materials and collections of epithelioid cells. Occasional Langhan's giant cells were also noticed. It was suggested as a case of tuberculous lymphadenitis and the diagnosis was further confirmed by biopsy. The patient was treated with conventional antitubercular four-drug regime for 6 
months and was given supplementary thyroxin therapy. She was followed up for another one and half years and was found to be free from any sort of recurrence. She remains in good health with thyroxin support at the time of writing.

\section{Discussion}

Most occult papillary carcinomas grow slowly and probably remain occult for the life of the patient. ${ }^{12}$ In this particular case, the thyroid lesion was not clinically suspected to be a papillary carcinoma. It was provisionally diagnosed as nodular goiter, which on FNAC was diagnosed as nodular goiter harboring occult papillary carcinoma. Aspirates from multiple sites revealed features of colloid goiter except at one site where cytological picture was suggestive of papillary carcinoma. It was hence considered as a case of $\mathrm{N}$ harboring occult papillary carcinoma. Many authors have mentioned about the slow growth and innocuous behavior of occult carcinoma. Well-differentiated papillary carcinoma and their metastasis are generally slow growing; patient may live without symptom for over 35 years. ${ }^{13}$ Most papillary carcinomas of the thyroid probably remain occult until death and only rarely do they cause death. Now a days many authors have described the unnecessity of removing all thyroid tissue in cases of occult carcinoma. ${ }^{14,}$ is $\mathrm{A}$ retrospective study carried out on 137 patients at the Mayo clinic, Rochester has shown that this type of carcinoma with or without nodal metastasis is a nonlethal curable disease when treated by conservative surgical means. Radical surgical or total thyroidectomy is unnecessary in the treatment of the disease. ${ }^{16}$ Regarding site of nodal metastasis there had been several studies also. Mirallie E; Visset J; Sagan C et $\mathrm{al}^{17}$ had performed a retrospective study for precise focalization of cervical node metastasis of papillary thyroid carcinoma. Aim of the study was to map their cervical involvement. They reviewed a series of 119 patients who had undergone total thyroidectomy with cervical lymph node dissection. The most frequent ipsilaterally involved sites were paratracheal $(46.7 \%)$ and midjugular $(34.2 \%)$ areas. Supraclavicular $(16 \%)$ and jugulodigastric $(4.1 \%)$ sites were less frequently involved. Our patient presented with jugulodigastric lymphadenopathy.

The patient had undergone total Thyroidectomy operation and was prescribed oral thyroxin tablet. She was also advised for Radioiodine scanning and $\mathrm{I}^{131}$ ablation therapy. Neither she received radioiodine therapy nor she took oral thyroxin supplementation. Within few months of surgery she suffered from low grade fever and noticed a swelling in her neck. The enlarged cervical lymph node was later on diagnosed as tuberculous lymphadenitik. Authors propose that in this particular case ablation of total thyroid immunocompromised the patient to some degree. Also she did not take oral thyroxin supplementation which might have further deteriorated her immune status. It is well recognized that suppressed immunological function can result in increased incidence and severity of infectious diseases. Many authors have suggested that total thyroidectomy suppresses both humoral and cell mediated immunity during subsequent days or months of surgery. ${ }^{18,19}$

\section{Conclusion}

The study emphasizes that, instead of total thyroidectomy, lobectomy or subtotal thyroidectomy should be the surgical regime for cases of occult papillary earcinoma whether or not is it associated with nodular goiter. Postoperative radioactive jodine therapy or any other radiotherapeutic measure is also not recommended for these cases. ${ }^{14,} 15,16$ The study indicates the importance of performing routine ultrasound (US) examinations and US-guided FNAC (US-FNAC) in the management of diffuse or nodular goiter in order to decide the mode of surgery. ${ }^{10 .}$ "It is also recommended that FNAC should be routinely performed in the evaluation of enlarged neck nodes in patients with previous thyroid carcinoma. 
In our subcontinent, tuberculosis is one of the commonest causes of cervical lymphadenopathy, and therefore one should always keep it in mind before suspecting a case as secondary metastasis whenever a patient presents to a physician with such a clinical setup.

\section{References}

1. Headinger CE, Williams ED and Sobin LH. Histological typings of Thyroid tumours. Ed. 2, Berlin, 1988, Springer-verlag.

2. Karle O Franssila. Thyroid gland. In: Jonn M Kissane ed. Anderson's pathology. 9th Ed: 1990:1559-1560.

3. David 4 B Ashley. Tumours of the thyroid gland. in: Ivan's histologicai Appearances of tumours. $4^{\text {th }}$ Ed; $1990: 301 \& 302$.

4. Francis $H$, Fukunaga and Ryuichi $Y$ Atani. Geographic pathology of occult thyroid carcinoma. Cancer $1975 ; 36: 1095-1099$.

5. Hazard JB, Crie G, Dinsmore AS, Hawk WA, Kenyon R, Neoplasms of the thyroid. Classificalion, morphology and treatment. Archives of pathology $1949 ; 59-502$.

6. Russel WO, Ibanez ML, Clark RL, While EC. Thyroid carcinoma; classification, intraglandular dissemination and clinicopathological study based upon whole organ sections of 80 glands. Cancer 1963; 16;1425.

7. Silliphant WM, Klinck GH, Levintin MS. Thyroid cancer and death: A clinicopathological study of 193 autopsies. Cancer 1964; 17:513.

8. Bhatt ON, Millar A, Le Riche J, King EG; Aspiration biopsy in pulmonary opportunistic infections. Acta Cytol 1977; 21:206-209.

9. Schultenover SJ, Ramiy I, Page CP, LeFebre SM, Crug AB. Needle aspiration biopsy: Role and limitations in surgical decision making. American $J$ Clin Pathol 1984; 82:405-410.
10. Kimoto T, Suemitsu K. Eda I, Shimizu T, Ohtani M, Nebika $T$. The effeciency of performing ultrasound guided fine-needle aspiration biopsy following mass screening for thyroid tumors to avoid unnecessary surgery. Surg Today 1999; 29(9): 880-883.

11. Lind $p$. Multi-tracer imaging of thyroid nodules: is there a rle in the preoperative assessment of nodular goiter? Eur J Nucl Med 1999 Aug; 26(日): 795-797

12. Brierre JT and Dickson LG. Clinically unsuspected thyroid diseases, GP 1964; 30:94. 98.

13 Shelley WB, Beerman $H$ and Enterline HT. Metastatio thyroid carcinoma, JAMA 1973; 226:173-174.

14. Vickery AL, Carcangiu ML Lohanessen JV, Sobrinho SM. Papillary carcinoma. Semin Diagn Pathol 1985; 2(2):90-100.

15. Harach HA, Franssila KO, Wasenius VM, Occult papillary carcinoma of the thyroid. A 'normal' finding in Finland. A systematic autopsy study. Cancer $1985 ; 56(3): 531-538$.

16. Hubert JP, Kiernan PD, Beahrs $\mathrm{OH}, \mathrm{Mc}$ Conahey WM, Woolner LB. Occult papillary carcinoma of thyroid. Arch Surg 1980; 115(4); 394-398.

17. Mirallie E, Visset J, Sagan C, Hamy A, Le Bodic MF, Paineau J. Localization of cervical node metastasis of papillary thyroid carcinoma. World J Surg 1999 Sep; 23(9): 970-973.

18. LungE, Galanti MR. Chapter 4: immunotoxicity. In: A text book of Endocrinology. 5th Ed; 1998: 298-302.

19. Timmermann W. Hamelmann W, Thiede A. Surgical procedures of the neck. Zentralbl Chir $1999 ; 124(5): 43-52$ 